\title{
Hospital employees' perceptions of fairness and job satisfaction at a time of transformational change
}

\begin{abstract}
Objective. This study examines the relationships between job satisfaction and organisational justice during a time of transformational change.

Methods. Data collection occurred immediately prior to a major regional hospital's move to a greenfield site. Existing measures of job satisfaction and organisational justice were used. Data were analysed $(n=316)$ using descriptive, correlation and regression methods together with interactions between predictor variables.

Results. Correlation coefficients for satisfaction and organisational justice variables were high and significant at the $\mathrm{p}<.001$ level. Results of a robust regression model (Adjusted $\mathrm{R}^{2}=.568$ ) showed all three components of organisational justice contributed significantly to employee job satisfaction. Interactions between the predictor variables showed that job satisfaction increased as the interactions between the predictor variables increased.

Conclusions. The finding that even at a time of transformational change staff perceptions of fair treatment will in the main result in high job satisfaction extends the literature in this area. Also, increasing rewards for staff who perceive low levels of organisational justice does not increase satisfaction as much as for staff who perceive high levels of fairness. If people feel negative about their role, but feel they are well paid, they probably still have negative feelings overall.
\end{abstract}


What is known about the topic? Despite much research highlighting the importance of job satisfaction and organisational justice in healthcare, no research has examined the influence that transformational change, such as a healthcare organisational relocation, has on these factors.

What does this paper add? During transformational change staff perceptions of fair treatment will mainly result in high job satisfaction. This is an important finding that adds to academic literature relating to job satisfaction and organisational justice. However, increasing rewards for staff who perceive low levels of organisational justice does not increase satisfaction as much as for staff who perceive high levels of fairness. If people feel negative about their role, but feel they are well paid, they probably still have negative feelings overall.

What are the implications for practitioners? Financial rewards do not necessarily motivate but low rewards do demotivate. Shortages of health professionals are often linked to job satisfaction, and recruitment and retention strategies are often based on salary.

\section{Introduction}

Job satisfaction (JS) and organisational justice (OJ) have been shown to be important variables in contemporary workplaces. Despite their importance no research into JS and OJ has been conducted in a healthcare organisation during a time of transformational change. The aim of this study is to address the gap in literature by researching employee perceptions of OJ and JS during the relocation of a hospital to a greenfield site. The research also identifies important issues for practitioners, particularly in the areas of employee selection and appraisal.

Population ageing, the changing patterns of diseases, new funding models, and changes in worker expectations have meant that healthcare providers need to rethink the way they manage

their workforce. ${ }^{1}$ The challenges for management are evident with health care providers 
currently experiencing global shortages of skilled health care workers. ${ }^{2}$ Shortages of skilled workers have been exacerbated by changes in the nature of the work, the poor image of nursing as a career, the ageing workforce, changes in technology and the impact of globalisation. ${ }^{2-4}$ When transformational change occurs within a health care organisation there is a need to focus on the perceptions that employees have about their workplace in order to minimise turnover and negative work outcomes such as loss of productivity and increased stress associated with the change. Many healthcare transformations fail because they overlook the importance of personal change. ${ }^{5}$ Individual transformation needs to parallel that of the organisation, and staffs perceptions of management as well as existing levels of job satisfaction impact on how well individuals adapt to the new normal. ${ }^{5}$

Additionally, models of health service delivery have needed to respond to enhanced consumer expectations, shrinking budgets and the performance expectations of both providers and recipients of health care. ${ }^{2,6}$ Consequently, there is a need for better understanding of the perceptions of healthcare employees providing care and how the workplace environment can be enhanced. Two factors that have been identified as strongly influencing the work environment are JS and OJ. Despite much research relating to JS and OJ in healthcare no research has examined these factors at a time of transformational change, such as a healthcare organisational relocation. This has led to a gap in literature that this study aims to address through the research question: How do staff perceive organisational justice and job satisfaction during transformational change?

\section{Literature Review}

Job satisfaction as a research construct originated from early motivational theories of employee behaviour within the disciplines of organisational behaviour and psychology, and has been 
extensively investigated within literature. Theories focused on the positive or negative feelings an individual has about their job in general ${ }^{7}$, and have resulted in multiple definitions of job satisfaction. For example, one definition of job satisfaction is "the extent of positive emotional response to the job resulting from an employee's appraisal of the job as fulfilling or congruent with the individual's values". ${ }^{8}$ Another focuses on the feelings that an employee has towards his or her work ${ }^{9}$ and yet another focuses on the attitudinal component of individuals towards their job by defining job satisfaction as the extent to which people like or dislike their jobs. ${ }^{10}$ The extent to which people like or dislike their jobs, as proposed by Spector ${ }^{10}$, is the approach to JS used in this study.

Job satisfaction has long been established as a factor that affects employees' intentions to stay and leave. ${ }^{11-13}$ Research has consistently found a negative relationship between job satisfaction and intentions to leave, and a positive relationship with intentions to stay. In addition to research into employee turnover JS has also been linked to organisational well-being. ${ }^{14}$ However, the healthcare sector has struggled with fostering this important job attitude due to a turbulent environment, which often results in poor quality of work life, burnout, and decreased job satisfaction. ${ }^{15}$ It does seem that JS is integral to maintaining a functioning workforce able to provide the services expected by patients, the health service and governments.

One of the factors believed to impact on JS is perceived justice. ${ }^{16}$ Research has suggested that OJ has important effects on individual employee attitudes, such as satisfaction and commitment, and individual behaviours, such as absenteeism and citizenship behaviour. ${ }^{16}$ Organisational justice describes the role that fairness plays in the workplace. ${ }^{17}$ Specifically, organisational justice is concerned with the ways in which employees determine if they have 
been treated fairly in their jobs and the ways in which those determinations influence other workrelated variables". ${ }^{17}$ Two types of OJ are procedural justice and distributive justice.

Greenberg and Tyler ${ }^{18}$ define procedural justice as perceptions of fairness in the means used to make decisions. Studies have shown that higher levels of perceived procedural fairness result in higher commitment. ${ }^{19,20}$ In contrast, distributive justice is concerned with the way rewards are perceived as being fairly distributed within the organisations. In other words, it refers to the fairness of the rules and procedures by which the rewards are distributed. ${ }^{21}$ Tyler ${ }^{22}$ argues that distributive justice is about people caring about the justice of allocation and decision-making procedures. When attempting to understand employee perceptions around JS it seems that perceived procedural fairness and distributive justice should be considered in order to understand further the factors influencing JS.

Procedural fairness and distributive justice may also be seen as way of offsetting or avoiding negative work environments. Fairness and justice are concepts that could be argued to be of significant importance, particularly in situations where there is uncertainty; such as a hospital's move to a new greenfield site. Where situations provoke uncertainty, as with the relocation of a work site, feelings of doubt, uncertainty and confusion are likely to provide the stimulus for seeking and using fair judgments. ${ }^{23}$ Issues relating to JS and OJ are of significant consideration for hospital managers attempting to direct large-scale organisational change. Negative impacts include links with retention, turnover, lower job satisfaction, and lower work commitment. Thus, JS and OJ are intrinsically linked and the significance of further investigating the link between the two is established.

The context of the study 
The importance of the links between JS and OJ is evident in the context of this study. The hospital was preparing to move to a greenfield site affiliated and co-located with a university precinct. The service relocation involved the largest patient transfer in Australia's healthcare history. ${ }^{24}$ Approximately 4,000 staff from professional, clinical, administration and operational streams were involved in the move. At the greenfield site the hospital provides new and expanded services, state of the art educational facilities, on-site research facilities, on-site parking, excellent public transport, and purpose built design to enhance patient safety and privacy. The former facility, at 54,000 square metres of floor space and in one central building, was significantly smaller than the new facility with over 170,000 square metres of floor space and seven core buildings. In line with enhanced community expectations for regional selfsufficiency, new services planned for the site include neonatal intensive care, improved radiation therapy services, trauma response unit, neuroscience and cardiac surgery. The strategic vision was that the new $\$ 1.76$ billion hospital would play a critical role in developing clinical leaders in the future by providing opportunities in teaching, research and complex clinical care. ${ }^{25}$

Moreover, in addition to the challenges of the relocation, in the 12 months prior to the study commencing, there had been a new State Government elected foreshadowing significant budget cuts, subsequent job losses, realignment in the governance of health from a highly centralised model to a decentralised structure governed by a local hospital and health service board, and extensive turnover of executive staff at a local level, including the commencement of a new chief executive. Re-engineering of health care systems is associated with a rapid restructuring of organizational structures. ${ }^{26}$ In a context of relocation this had resulted in redundancies, redeployments, the emergence of new roles and models of care and enhanced risks to both the organization and the individual. All together, the staff had to deal with an extraordinary situation 
at the governmental and the local level. At a service level, the roles of the employees remained consistent with the professional standards expected of health care professionals and patient expectations remained constantly high. Organisational change in many industries is enabled by a reduction in services or activity. As an essential service, health does not have the option to close down so the background for our research provides a consistent demand for services at a local level, overshadowed by broader change. Data were collected in the month prior to the relocation.

This study reports on employees' perceptions of job satisfaction, procedural and role fairness, interactional justice, rewards and recognition within their organisation. The study is particularly salient and unique in the context of a large transformational change from the existing site to the new greenfield site, as no previous research has examined these factors within the context of this study.

\section{Hypotheses}

Given the importance of JS and OJ identified in previous research ${ }^{11-13,16}$ we hypothesise that in the context of the transformational change experienced by employees in moving from their existing work site to the new greenfield site:

Hla: Employee Satisfaction will be high when employees perceive improved distributive justice.

H1b: Employee Satisfaction will be significant when employees perceive that they are treated fairly with respect to their experience of managerial procedures.

H1c: Employee Satisfaction will be significant when employees perceive that they are treated fairly with respect to interactional justice. 
In addition to the direct effects anticipated above, we also hypothesise that employees' perceptions of fairness across these domains will positively interact, creating second-order moderating effects in anticipating employee satisfaction. In essence, we are suggesting that the various domains of organisational justice have both a direct and a cumulative effect in driving employee satisfaction. Our suggestion is that employees who feel that the organisation's management is proceeding with distributive, procedural and interactional justice concomitantly with have a heightened sense of satisfaction with their employer and workplace. Based on previous research that perceptions of procedural fairness are important and cumulative in engendering JS ${ }^{27}$ we hypothesise that:

H2: There will be a positive interaction between distributive justice, procedural justice and interactional justice in predicting employee satisfaction.

\section{Methods}

This study reports on a subset of a larger project, which aimed at studying the impact of the move on employee's both before and after the event. A mixed method approach was approved by the ethics committee and included a qualitative component of 50 staff interviews and a quantitative survey. This study reports only the results of JS and OJ quantitative components of the larger study.

\section{Participants}

A total of 3,000 employees across the health service were invited to participate in this study. These employees came from the entire region, which also included a smaller 250 bed hospital, a 63 bed sub-acute and non-acute health facility and numerous community public and mental 
health services. The extended services were selected as the impact of change extended beyond the immediate group of staff physically moving to the new facility.

\section{Procedure and ethics approval}

Ethics approval was received from the university and health care service prior to collecting data. Participants were then invited to participate through a number of methods including health service-wide email broadcasts, promotion via the monthly health service newsletter, and advertising at a number of staff forums. In preparation for the major move from the old hospital to the new, a number of "move forums" were scheduled and provided the opportunity to speak about the research and to make available hard copies of the survey tool. Hard copies were provided in de-identified envelopes with postage paid for return to the university. This was an important consideration to ensure that staff confidentiality was maintained.

The survey was disseminated both online and in hardcopy as some staff did not have access to the organisation's intranet or email. Operational staff from security, environmental and food services were included in the survey sample with distribution of the survey-questionnaire to senior staff who then passed the non-identifiable surveys on to others via a snowball recruitment method. Staff who chose to answer the survey-questionnaire online could access the nonidentifiable survey via announcements through the intranet system or direct link sent to their email.

\section{Measures}

The questionnaire contained demographic items regarding the respondent's gender, age, and role within the health service. We also used established measures of JS and OJ as follows.

\section{Job Satisfaction}


To measure JS we used Judge et al.'s ${ }^{14}$ eight-item overall job satisfaction measure. The reliability of this measure was high with Cronbach's $\alpha=.92$. An exemplar item from this measure is: "All in all, how satisfied are you with your job?"

\section{Organisational Justice}

To measure OJ we used Niehoff and Moorman's ${ }^{28}$ measure of distributive (five items), procedural (6 items) and interactional (9 items) justice. Reliability for these measures was high, with Cronbach's $\alpha=.83, .86$ and .95 respectively.

The first step in the data analyses process for OJ was a principle component analysis (PCA) to ensure all questions loaded appropriately on their respective scales. Analysis used promax rotation, and confirmed that all variables loaded appropriately onto the factors intended as per Niehoff and Moorman's ${ }^{28}$ original study.

\section{Results}

A total response rate of $10.5 \%$ was achieved (316 surveys). Of these, 248 were female $(78.5 \%)$, 64 were male $(20.3 \%)$ and 4 were not disclosed $(1.3 \%)$. The majority of participants were employed on a permanent full time basis $(67.1 \%)$, with the remainder either on a permanent part time $(19.6 \%)$, casual $(4.1 \%)$, temporary $(7.9 \%)$ or other contract $(1.2 \%)$. The sample also included majority of non-indigenous workers (96.5\%). Table 1 provides the descriptive statistics and bivariate correlations for the variables investigated.

\footnotetext{
*Insert Table 1 here*
} 
As shown in Table 1, all variables relating to JS and the components of OJ were significantly and positively correlated, with relatively high and strongly significant coefficients. The control variables age and gender did not have a significant correlation with the derived variables, but were retained for the regression analyses.

In order to examine the impact that perceived role, fairness and rewards, and recognition had on employee satisfaction a regression analysis was conducted. Table 2 presents the regression model results, including the results for the hypothesised interaction effects in the final stepwise model.

*Insert Table 2 here*

Regression analysis produced a robust model that explained $54.6 \%$ of variance in employee satisfaction. All three perceived justice scales highlighted significant relationships with employee satisfaction in line with hypotheses $1 \mathrm{a}, 1 \mathrm{~b}$ and $1 \mathrm{c}$. As the three perceived justice variables investigated - distributive justice, procedural justice and interactional justice - do play a significant role in affecting employee satisfaction in times of change and hypotheses $1 \mathrm{a}, 1 \mathrm{~b}$ and 1c are supported.

Interaction terms were added to the regression model in its final iteration. This final model integrated the three pairwise interactions of the three justice items, along with the three-way interaction term for these items. The three way interaction, which is shown to be significant (at $\mathrm{p}$ $<.01)$ supports hypothesis 2 and is shown at Figure 1.

*Insert Figure 1 here* 


\section{Discussion}

In this study we extend existing literature to examine the job satisfaction and organisational justice perceptions of employees within a health district undergoing significant transformational change in a move to a new greenfield site. In hypotheses 1a to $1 \mathrm{c}$ we tested the notion that even at times of transformational change JS will be high when employees perceive they are being treated fairly in terms of distributive justice, procedural justice and interactional justice. Similar to previous research ${ }^{11-13}$, the analysis in this study supported these hypotheses. These findings are particularly important in the context of transformational change, as while previous research has hypothesised that where situations provoke uncertainty, as with the relocation of a work site, feelings of doubt, uncertainty and confusion are likely to provide the stimulus for seeking and using fair judgments ${ }^{23}$, little research has empirically tested this. Of the research that has tested these constructs in times of change, job insecurity as a result of change is associated with lower

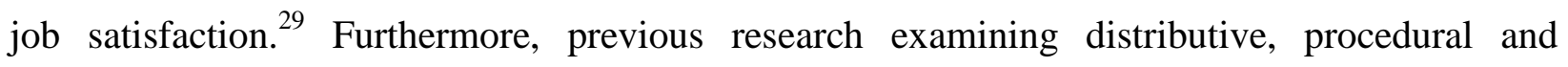
interactional justice has found that procedural justice and interactional justice are stronger predictors of evaluations of the organisation as a whole, whereas distributive justice relates more closely to personal outcomes within the organisation. ${ }^{19}$ Thus in times of transformational change, the findings of the present study provide an important insight into perceived employee fairness of both organisational and employee outcomes.

When we examined the interactions between predictor variables at low and high levels of interactional justice (Figure 1), we looked at two further groups - namely those who reported low and high distributive justice (rewards) and those who reported low and high procedural justice. We noted that high interactional justice combined with high procedural justice (even with 
combined with low distributive justice) provided a point estimate for satisfaction almost equivalent to a high report for all three justice domains. This is in line with previous work by Brockner and Wiesenfeld ${ }^{27}$ who also found the same results in their meta-analysis and concluded that "it is not only what you do, but how you do it" that matters when it comes to perceived justice and organisational outcomes. In our sample, even those employees feeling aggrieved in relations to their relative rewards were satisfied if they felt their status quo was the result of fair processes in relation to procedure and interactional-fairness issues.

The finding, which supports hypothesis 2 , suggests that if people feel they have an unfair rewards structure, but this has been as a result of what they see as a fair process, they are not too upset about it. The finding was also in line with previous research ${ }^{30}$, which demonstrated this finding using a quasi-experimental design of performance appraisal outcomes. This has important implications for managers, and suggests that managers should continue to follow "due process", even though the hierarchical emphasis may be increasingly on managerial outcomes. Even where managerial outcomes are perceived as less than desirable, they appear to be more acceptable to staff when fair procedures have been followed.

This study also found that increasing rewards (distributive justice) for the low fairness groups does not increase satisfaction as much for this group as for the high role fairness group. This is consistent with research regarding tangible rewards and satisfaction. In particular, financial rewards are seen as a hygiene factor where adding money does not necessarily motivate but the absence of it does demotivate ${ }^{31}$. If people feel negative about their role, but feel they are well paid, they probably still have negative feelings overall. This is an important finding, especially for practitioners, as shortages of health professionals are often linked to job satisfaction, while strategies used to increase recruitment and retention of staff frequently focus 
on salary. Herzberg et al ${ }^{31}$ identified motivators such as achievement, advancement, recognition, responsibility, professional growth and the work itself as more powerful in influencing job satisfaction. It has been argued that these factors are core constructs to professional practice models for nurses ${ }^{32}$ whereas medical career satisfaction is highly linked to clinical competency, teaching and research activities and professional accomplishment. ${ }^{33}$

\section{Limitations}

A limitation of our study is that all the groups surveyed have been aggregated. Also, the response rate of $10.5 \%$ is a low response, though the researchers found no significant variation between the sample and the general population within the Health District. Also, the workforce comprised $78.5 \%$ females, which needs to be considered if findings are to be translated to other workforces.

Previous research concluded that job satisfaction increases with advancing age, and discontent was related to decreasing professional autonomy. There are also differences amongst medical specialities in that anaesthetists and hospital based doctors did not show the trend of increasing job satisfaction as did psychiatrists and non-hospital medical practitioners. ${ }^{34}$

The above limitations suggest that remedies to improve work place satisfaction may need to be disaggregated. Our sampling strata within small professional groups (for example, dentists and doctors) did not allow for an investigation of these effects within these professional groups and this will be considered in future research.

\section{Conclusion}

The study considered how staff perceived organisational justice and job satisfaction during transformational change in a hospital's move to a greenfield site, and researched an important and under-researched area of health research. The study found that if staff feel a sense of 
injustice in terms of their role, or the managerial procedures leading to decisions in relation to their role, they will tend to report lower levels of satisfaction. This loss of satisfaction is only partially mitigated through a sense of rewards and recognition fairness.

Further research is needed to gauge if this relationship is evident across other healthcare settings and if so, to examine wider organisational implications for healthcare practitioners and academics. In addition, further research is needed on how our conclusions are related to other workplace attitudes and behaviours such as work commitment and citizenship behaviours. 


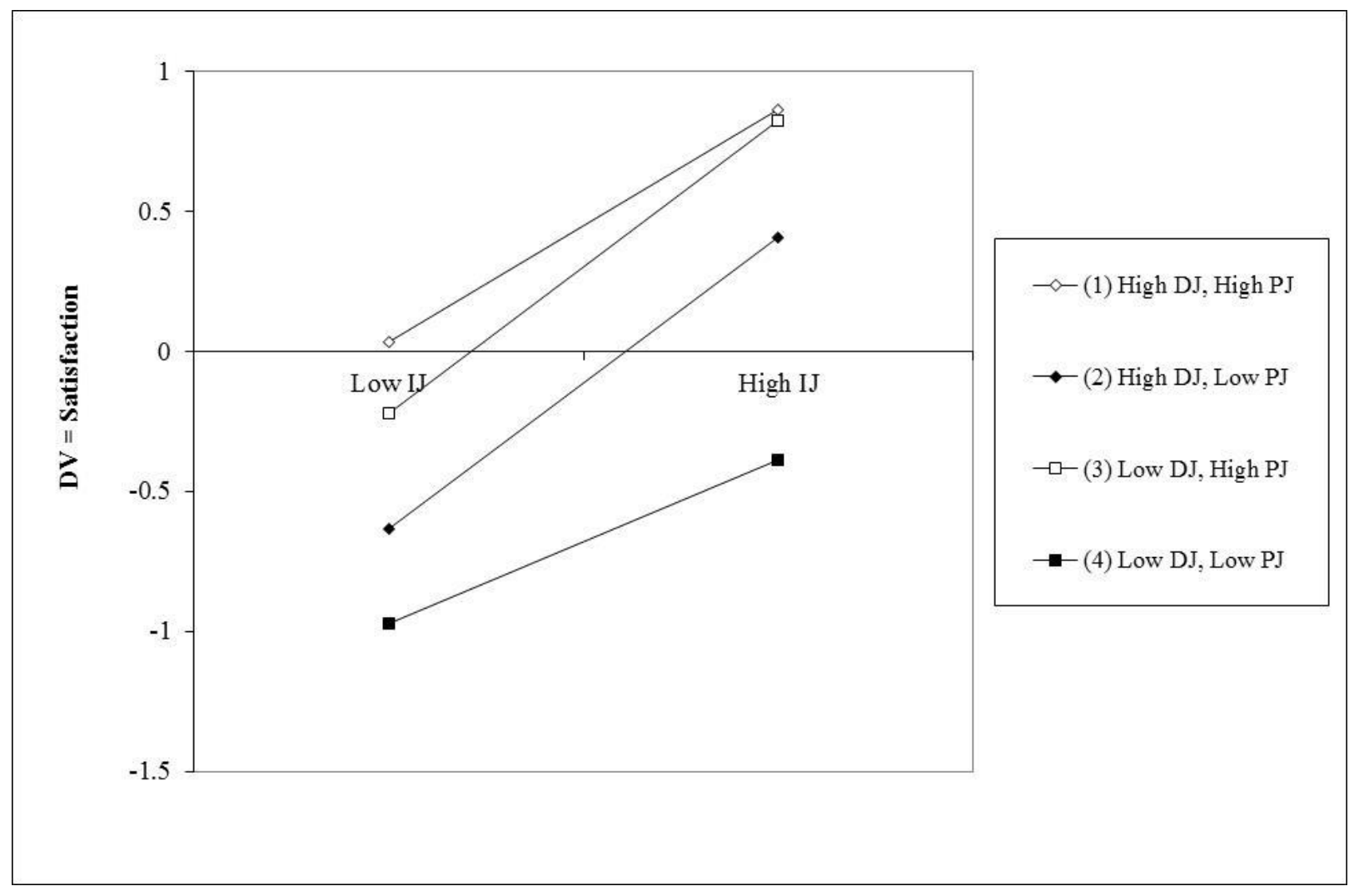

Figure 1: Three-way interaction of organisational justice terms 
Table 1: Descriptive and correlation variables

\begin{tabular}{|l|l|c|c|c|c|c|c|c|c|}
\hline & Mean & SD & $\mathrm{N}$ & 1 & 2 & 3 & 4 & 5 & 6 \\
\hline 1. Age & 3.98 & 1.05 & 312 & & & & & & \\
\hline 2. Gender & 1.21 & 0.40 & 313 & .037 & & & & & \\
\hline $\begin{array}{l}\text { 3. Distributive } \\
\text { Justice }\end{array}$ & 0.00 & 1.00 & 290 & -.054 & -.048 & $(.83)$ & & & \\
\hline $\begin{array}{l}\text { 4.Procedural } \\
\text { Justice }\end{array}$ & 0.00 & 1.00 & 274 & -.043 & .015 & $.417^{* * *}$ & $(.86)$ & & \\
\hline $\begin{array}{l}\text { 5. Interactional } \\
\text { Justice }\end{array}$ & 0.00 & 1.00 & 271 & -.075 & $-.126^{* *}$ & $.870^{* * *}$ & $.379^{* * *}$ & $(.95)$ & \\
\hline 6. Satisfaction & 0.00 & 1.00 & 265 & -.072 & -.069 & $.648^{* * *}$ & $.534^{* * *}$ & $.674^{* * *}$ & $(.92)$ \\
\hline
\end{tabular}

*Age was reported using on a six point scale $(1=$ under $21,2=21-30,3=31-40,4=41-50,5=$ $51-60,6=$ over 60 ). Gender was coded $1=$ female, $2=$ male. Job satisfaction and fairness scales are standardised scores, mean centred at zero with an $\mathrm{SD}$ of 1.00. Alphas are in brackets along the diagonal. $* \mathrm{p}<.1, * * \mathrm{p}<.05, * * * \mathrm{p}<.001$ 
Table 2: Regression analysis

\begin{tabular}{|c|c|c|c|c|c|c|}
\hline & $\beta$ & $\mathrm{SE}$ & $\beta$ & SE & $\beta$ & $\mathrm{SE}$ \\
\hline Intercept & .432 & .288 & .013 & .222 & -.0101 & .2257 \\
\hline \multicolumn{7}{|l|}{ Controls } \\
\hline Gender & -.171 & .144 & -.023 & .110 & -.0362 & .1101 \\
\hline Age & -.059 & .057 & -.001 & .043 & .0065 & .0427 \\
\hline \multicolumn{7}{|l|}{ Direct Effects } \\
\hline Distributive Justice (DJ) & & & $.185 * *$ & .090 & $.1771 * *$ & .0899 \\
\hline Procedural Justice (PJ) & & & $.312 * * *$ & .048 & $.3856 * * *$ & .0661 \\
\hline Interactional Justice (IJ) & & & $.383 * * *$ & .089 & $.4370 * * *$ & .0924 \\
\hline \multicolumn{7}{|l|}{ Interaction Effects } \\
\hline $\mathrm{DJ} * \mathrm{IJ}$ & & & & & .0300 & .0467 \\
\hline $\mathrm{DJ} * \mathrm{PJ}$ & & & & & -.1054 & .0879 \\
\hline $\mathrm{IJ} * \mathrm{PJ}$ & & & & & .0321 & .0972 \\
\hline $\mathrm{DJ} * \mathrm{IJ} * \mathrm{PJ}$ & & & & & $-.0842 *$ & .0434 \\
\hline $\begin{array}{l}\mathrm{F} \text { and (Sig. F Change) } \\
\mathrm{R}^{2}\end{array}$ & $\begin{array}{r}1.264 \\
.\end{array}$ & .284 & $\begin{array}{r}56.89 \\
.6\end{array}$ & .000 & $\begin{array}{r}32.58 \\
.5\end{array}$ & $8^{.0535}$ \\
\hline
\end{tabular}

$* \mathrm{p}<.1$ level, ** $\mathrm{p}<.05 * * * \mathrm{p}<.001$ level 


\section{References}

1. AlHW. Australia's health series 12. Canberra: Australian Institute of Health and Welfare; 2010.

2. Mangham L, Hanson K. Scaling up in international health: what are the key issues. Health Policy and Planning. 2010;25(2):85-96.

3. Lee L, Weir T, Markotsis D. Social impacts of the new economy. Canberra: Department of Industry, Tourism and Resources, New Economy Branch; 2002.

4. Leurer M, Donnelly G, Domm E. Nurse retention strategies: Advice from experienced registered nurses. Journal of Health Organization and Management. 2007;21(3):307-319.

5. Souba W. Health care transformation begins with you. Academic Medicine. 2015;90(2):139142.

6. HWA. National Health Workforce Innovation and Reform Strategic Framework for Action Adelaide: Health Workforce Australia; 2011.

7. Lu H, While A, Barriball K. Job satisfaction among nurses: A literature review. International Journal of Nursing Studies. 2005;42(2):211-227.

8. Morris $\mathrm{M}$, Venkatesh $\mathrm{V}$. Job characteristics and job satisfaction: understanding the role of enterprise resource planning system implementation. MIS Quarterly. 2010;34(1):143.

9. Price J. Reflections on the determinants of voluntary turnover. International Journal of Manpower. 2001;22(7):600-624.

10. Spector P. Job satisfaction: Application, assessment, causes and consequences. Thousand Oaks: Sage; 1997.

11. Castle N, Engberg J, Anderson R, Men A. Job satisfaction of nurse aides in nursing homes: Intent to leave and turnover. The Gerontologist. 2007;47(2):193-204.

12. Larrabeen J, Wu Y, Persily $\mathrm{C}$, et al. Influence of stress resiliency on RN job satisfaction and intent to stay. Western Journal of Nursing Research. 2010;32(1):81-102.

13. McCarthy G, Tyrrell M, Lehane E. Intention to 'leave' or 'stay' in nursing. Journal of Nursing Management. 2007;15(3):248-255.

14. Judge T, Boudreau J, Bretz R. Job and life attitudes of male executives. Journal of Applied Psychology. 1994;79(5):767.

15. Gilbert S, Laschinger $\mathrm{H}$, Leiter $\mathrm{M}$. The mediating effect of burnout on the relationship between structural empowerment and organizational citizenship behaviours. Journal of Nursing Management. 2010;18(3):339-348.

16. Colquitt J, Conlon D, Wesson W, Porter C, Ng K. Justice at the millennium: A meta-analytic review of 25 years of organizational justice research. Journal of Applied Psychology. 2001;86:425-445.

17. Moorman R. Relationship between organizational justice and organizational citizenship behaviors: do fairness perceptions influence employee citizenship. Journal of Applied Psychology. 1991;76(6):845.

18. Greenberg J, Tyler T. Why procedural justice in organizations? . Social Justice Research. 1987;1(2):127-142. 
19. McFarlin D, Sweeney P. Research notes. Distributive and procedural justice as predictors of satisfaction with personal and organizational outcomes. Academy of Management Journal. 1992;35(3):626-637.

20. Brockner J, DeWitt R, Grover S, Reed T. When it is especially important to explain why: Factors affecting the relationship between managers' explanations of a layoff and survivors' reactions to the layoff. Journal of Experimental Social Psychology, . 1990;26(5):389-407.

21. Alexander $S$, Ruderman $M$. The role of procedural and distributive justice in organizational behavior. Social Justice Research. 1987;1(2):177-198.

22. Tyler R. The psychology of procedural justice: A test of the group-value model. Journal of Personality and Social Psychology. 1989;57(5):830.

23. Heponiemi $T$, Elovainio $M$, Kouvonen $A$, et al. The effects of ownership, staffing level and organisational justice on nurse commitment, involvement, and satisfaction: A questionnaire study. International Journal of Nursing Studies. 2011;48(12):1551-1561.

24. Capper S. Gold Coast University Hospital opens after Australia's biggest planned hospital move. ABC News. 2013. http://www.abc.net.au/news/2013-09-28/gold-coast-universityhospital-opens-after-patients-transferred/4987054.

25. GCHHS. The State of Queensland (Gold Coast Hospital and Health Service) annual report 2012-2013. Brisbane: Queensland Government; 2013.

26. Alaszewski A. Risk, safety and organizational change in health care. Health, Risk \& Society. 2005;7(4):315-318.

27. Brockner J, Wiesenfeld B. An integrative framework for explaining reactions to decisions: interactive effects of outcomes and procedures. Psychological Bulletin. 1996;120(2):189208.

28. Niehoff B, Moorman R. Justice as a mediator of the relationship between methods of monitoring and organizational citizenship behavior. Academy of Management Journal. 1993;36:527-556.

29. Ashford S, Lee C, Bobko P. Content, causes and consequences of job insecurity: A theorybased measure and substantive test. Academy of Management Journal. 1989;4:803-829.

30. Taylor M, Tracy K, Rebard M, Harrison J, Carroll S. Due process in performance appraisal: A quasi experiment in procedural justice. Administrative Science Quarterly. 1995;40:495-523.

31. Herzberg F, Mausner B, Snyderman B. The Motivation to Work. New Brunswick: John Wiley \& Sons; 1959.

32. McGlynn K, Griffin M, Donahue M, Fitzpatrick J. Registered nurse job satisfaction and satisfaction with the professional practice model. Journal of Nursing Management. 2012;20(2):260-265.

33. Hojat M, Kowitt B, Doria C, Gonnella J. Career satisfaction and professional accomplishments. Medical Education. 2010;44(10):969-976.

34. Nylenna M, Gulbrandsen $\mathrm{P}, \mathrm{F} \varnothing \mathrm{rde}$ R, Aasland O. Unhappy doctors? A longitudinal study of life and job satisfaction among Norwegian doctors 1994-2002. BMC Health Services Research. 2005;5:44. 